\title{
Research on Spatial Modeling of Urban Transportation Networks using GIS
}

\author{
Aamudalapelli Anjali, Santhosh Kumar
}

\begin{abstract}
-delivery availability is a substantial motive force of city development and key to the possible development of metropolis agencies. This paper famous a number one GIS-based totally tool created to permit the short research of availability by way of diverse vehicle modes. supposed to be adaptable and use brazenly available statistics, this device (worked in ArcGIS) makes use of summed up fee to quantify shipping charges crosswise over systems which include financial and separation components. The paper displayed three fundamental avenue set up availability assessing hints, provided hypothesis premise of the model development in detail, and the version development technique. Taking Foshan town as an example, the models had been tried utilising the metropolis street set up statistics. At final, further urban street prepare availability evaluation fashions are mentioned. The shape contemplations and statistics necessities for executing a GIS-based totally metropolis transportation research framework are broke down and part of the economically on hand GIS programming is assessed. Accentuation is ready on the utilization of a GIS in version-prepare transportation programs as opposed to with appreciate to specific capability employments of GIS. some utilizations of GIS approach for city transportation research are portrayed.
\end{abstract}

\section{PRESENTATION}

The town avenue device assumes a key activity in the city spatial shape. it is the precept metropolis social-financial gadget physical sports and transportation transporter. today, an ever growing range of scientists recognition on street arrange. one of the most sizable problems is the way to evaluate the openness of street prepare. Hansen proposed the openness idea just because, characterizes it because the vehicle set up in special hubs collaboration possibility (Hansen, 1959). inside the destiny, the supply extensively related in studies and road machine plan, improvement, and evaluation. inside the transportation topography, the road arrange openness assessment has taken as a big trouble. site visitors clog has grew to become out to be one of the maximum squeezing troubles in urbanized territories around the globe. The electricity of the automobile due to the fact the technique of choice, the proceeding with partition among occupations and lodges, and the departure from the focal commercial enterprise region (CBD) to suburbia have introduced to exquisite stages of web page traffic blockage and unfavorably stimulated air pleasant. Advances in innovation can assist transportation establishments of their endeavors to continuously create expound new techniques for website site visitors the board. One new innovation that

Revised Version Manuscript Received on 10, September 2019.

Aamudalapelli Anjali Research scholar Department of Civil Engineering from University of Technology,Jaipur, Rajasthan, India.(Email: aanjali2204@gmail.com)

Dr. Santhosh Kumar, Professor In Civil Dept, University Of Technology, Jaipur, Rajasthan, India.(Email: Sabbidvenkat2017@gmail.com) shows up specifically encouraging is the growing innovation of the topographical information framework (GIS).

Openness to employments, administrations or special goals of intrigue, has for pretty a while been perceived as key to the development of on your rate variety car, land use and spatial arranging methodologies [1-5]. improved accentuation on low-cost urban development has underlined the significance of availability for (I) monetary development as it empowers the development of people and merchandise to assist the running of the economic system [6]; (ii) natural targets, as an instance, diminishing ozone harming substance emanations and poisons that very last consequences from numerous automobile modes and how they're carried out [7]; and (iii) impartial access for all economic gatherings to middle administrations, for example, social coverage.

transport frameworks are key flow betweens of manageability in city regions, as they impact the manner in which individuals and products journey via a city, and henceforth the electricity (and alongside those lines carbon emanations) required to guarantee a town capacities effectively. nicely-structured low-carbon shipping frameworks can empower advances from high discharge to low outflow styles of vehicle (e.G., from private automobile to open vehicle or motorcycles). Spatial arranging can complement this with the useful resource of urging development to show up in zones of right network, making certain the association of low-carbon transport alternatives on the town plans, or organizing combined use improvements in which taking walks and biking are an increasing number of eye-catching picks to adventure.

models of automobile openness, and its cooperation with manageability, had been created over numerous years. Hansen demonstrated a solid courting among's the openness of a quarter internal a town and its ability to draw in new metropolis improvement or speculation. This idea come to be reached out through Lowry as a land-use shipping model in which the spatial detachment of (or the simplicity of motion amongst) populace and work is a key determinant of land-use (see Levinson for a later use of this kind of model). the ones fashions utilized estimations of time or separation in their assessment of manageability and as a result the carbon emanations of a voyage have been not taken into consideration. similarly upgrades in urban land-use shipping models make use of a scope of methodologies, frequently with frequently complex portrayals of town methods, yet fundamental to the ones models is the portrayal of automobile availability. Thusly, at the same time as availability 
computations have frequently been wrapped inner land-use delivery fashions, the significance of understanding openness in its personal privilege has all of the extra as of late precipitated the development of severa express openness apparatuses (see [5] for a survey of such devices implemented in Europe), a number of which might be impartial gadgets although others were created in a GIS domain.

\section{TRANSPORTATION FASHIONS AND INFORMATION INPUTS}

city Transportation making plans and Forecasting city transportation arranging as rehearsed in recent times in a massive portion of the western created worldwide places is predicated upon on overall displaying. The conventional city transportation arranging framework (UTPS) for movement studies and looking ahead to containing highlights of day trip age, dispersion , modular break up, and assignment is based upon intensely on conglomeration of spatial systems and statistics. Land use and statistic facts, for example, population, pay, and car proprietorship are to be had at disaggregate geology degrees; be that as it is able to, for transportation research functions they may be gathered to visitors examination zones (TA Zs). TAZs are notion to be homogeneous; the monetary and land use types that exist within the quarter are fell to a everyday zonal quantity and not the usage of a connection with the change of those characteristics.

Transportation framework is spoken to as a chart comprising of hubs and connections. Connections constitute street quantities, even though hubs talk to street crossing factors. The device utilized for demonstrating devices is a whole and disentanglement of the genuine bodily tool. as an instance, inside the San Francisco metropolitan locale the road system includes in more of 300,000 fragments, whilst the device applied for district large transportation exam consists of below 20,000 connections. The connections are frequently coded with out a reference to any shape of geographic reference framework; as a result, it is lumbering to relate installation information to unique areal trait information. The models, on this manner, are not sensitive to adjustments happening at lower spatial tiers. This device, confined on organizers because of computer rules formerly, has some essential ramifications. due to the fact that depending upon the degree of disaggregation, TAZs can talk to a populace of upwards of 10,000 humans within the San Francisco district for a population of 5,600,000 there are 770 zones-all intra-TAZ kinds in traits and internet works are misplaced. This supposition that is not excessively prohibitive for conventional immoderate-thickness urban situations with T AZ zones associated with a reasonably little vicinity. anyhow, the huge majority of the town improvement nowadays takes place in suburbia (6), in which accommodations and paintings .Densities are significantly lower. For this example, a T AZ vicinity can cowl a large territory and the presumption of homogeneity of movement and financial functions may be invalid.

Estimates of destiny journey use can be antagonistically encouraged by means of using the conglomeration of intra-T AZ structures and features. Modular desire is extremely impacted whilst it takes adventure creators to get to the

adventure station. Zonal midpoints for this variable , mainly in rural TAZs, regularly display massive get proper of access to times, along those lines biasing model results (7). The zonal everyday is classed without express concept of the real area of population, no matter the reality that this information is on the market all the way down to the square amassing stage. With a normal geographic reference framework, zonal midpoints can be evaluated as a the mixture of the entrance time of the only of a kind subzonal territories weighted by using the quantity of households.

\section{ESTIMATING SHIPPING PRICES AND ACCESSIBILITY}

there are various meanings of openness within the writing; although, a general definition thru Wachs and Kumagi [31] is that availability is the straightforwardness (or problem) that chances (e.G., business) or administrations may be come to from a place. Availability catches the exertion required to defeat the spatial department of regions, and greater often than not mirrors the utility (e.G., creating a trip from home to paintings) associated with going between those regions $[5,32,33]$. Geurs and Van Wee [3] deliver a entire audit of availability measures, however the most summed up definition of the openness, An, of place, I, is from Koenig

$$
A_{i}=\sum_{j} o_{j} f\left(C_{i j}\right)
$$

where $\mathrm{Oj}$ are the opportunities (utility or activity) to be gained from travelling to location $\mathrm{j}$, $\mathrm{Cij}$ is the distance, time, or cost of travelling from $\mathrm{i}$ to $\mathrm{j}$, and $\Gamma\left(C_{x y}\right)_{\text {Is a }}$ ability which guarantees that the openness increments due to the truth the charge of motion among regions diminishes. as a consequence, crucial to statistics availability is the price of motion among an inception and a purpose. This rate, or impedance, may be predicted in diverse approaches. The least complex degree is the Euclidian separation among which modified into typically carried out in earlier than examinations. Accessibility of automobile installation information has empowered steadily practical tool way examination of separation; the shorter the separation, the better the openness. in any case, this does not recollect the bodily gadget shape of vehicle modes or their particular financial overheads, speeds, frequencies, stages of exertion required of their utilization, change instances and bounds. therefore, on this artwork the price of movement is communicated as a summed up price, considering every time and financial elements of any journey along the car put together in a single positive together esteem. This makes the supposition that the price of motion among a starting point and motive may be generally communicated inside the shape:

\section{INFORMATION ASSETS}

Accessibility of automated facts puts together with data with apprehend to metropolis road systems is the pivotal factor a very good manner to impact the adequacy of GIS innovation in transportation arranging. A automatic statistics base of a avenue device have to contain forms of statistics, 
facilitate statistics and high-quality statistics, the preceding to show the geographic location of hubs or avenue convergences and the very last to depict attributes of the connections and the framework. arrange statistics are generally more than one $\mathrm{x}$ and $\mathrm{y}$ permits, even though high-quality records can be numeric or alphanumeric. The affiliation of property data within the information base can include a massive variety of factors expected to assist the planned applications. avenue name, quantity of paths, restriction, and location site traffic course are the most well-known trends. For geocoding, cope with reaches must be positioned away inside the records base, despite the fact that, for asphalt renovation programs, asphalt type and situation want to likewise be placed away as inclinations. The length of the relationship does no longer need to be expressly located away inside the facts base because it thoroughly may be evaluated from the $\mathrm{x}$ and $\mathrm{y}$ installation units of the hubs at the 2 elements of the bargains.

Of particular centrality for the appropriation of GIS frameworks in transportation arranging is the advent of the topologically coordinated geographic encoding and referencing (TIGER) record with the beneficial useful resource of the U.S. agency of the Census. The TIGER statistics framework have come to be supposed to robotize the mapping and associated geographic sports activities required to assist the 1990 enumeration and the other evaluation responsibilities of the assessment authority. The cause of the TIGER improvement exertion changed into to offer a automatic facts base that covers the general public of the united states and consists of information on street systems (every Interstate and, railroad tracks, actual electric powered cables, pipelines, water highlights (waterways, lakes, and streams), and regulatory or real territories (states, metropolitan areas, places, registration tracts, evaluation squares).

Concentrates from this record are discharged to the overall population and can frame the reason for structure the bottom manual in a GIS framework. The discharged records documents contain separate records for every road element with data on - Longitude and scope of starting and consummation focuses,

- avenue names,

- deal with extends on every facet of the street (for town zones in reality), and

- Statistical or managerial regions on each side of the road.

This information form might no longer expressly consist of facts on hubs; be that as it could, it offers suggestions to effects constructing up road crossing factors and distinguish hubs.

The FHWA supported a show project to survey the estimation of the TIGER data due to the fact the bottom guide of a GIS framework for website on line traffic the board and transportation arranging. The outcomes had been particularly reassuring. With the proper programming, TIGER data have been executed for growing advanced facts bases of a transportation installation low-price for motion request demonstrating, geocoding and showing on a manual data places together with statistics with recognize to website traffic signal and mishap areas, touching on $\mathrm{T}$ AZ zones to facts statistics, and planning a maximum confined way departure route.

regardless of the fact that TIGER documents can supply the idea of a complicated machine information base, upgrades and increases within the statistics are anticipated to help particular transportation applications. For some city districts, the TIGER files are out of date, and roads in as of overdue created zones and lacking place extents must be covered. The course or avenue characterization must be advanced to mirror restriction, just as avenue kind (Interstate roadway, country parkway, or community street). specific first-rate information, for instance, quantity of paths and placement visitors heading have to be included One-of-a-type wellsprings of superior tool facts include the automatic line diagrams (DLG) of the U.S. Geographical Survey or information available from business enterprise dealers (e.G., ETAK). within the event that computerized information are not reachable, they need to be digitized or tested from paper maps. Aenal (photogrammetric) and satellite $\mathrm{tv}$ for $\mathrm{pc}$ television for laptop photos are one among a kind hotspots for growing advanced structures. past due propels in innovation that coordinate raster and vector designs license the drawing of the boulevards over the satellite tv for pc television for laptop photos. At very last, the growing innovation of the worldwide situating framework (GPS) is particularly beneficial for hastily distinguishing the longitude and scope of any element on the road set up.

\section{EXECUTION OF GIS-BASED ABSOLUTELY VERSION \& RESULTS}

To building up an device that is conventional and transferable, prepared to widely diagnosed elegant GIS contribution to the form of spatial records, at a few random scale, and play out the summed up rate calculation to create a ramification of openness measures, an encompass become created in VBA for ESRI's ArcGIS@ $\odot$. The software program of this encompass come to be exhibited utilising a contextual research inside the greater London Authority (GLA) territory inside the united kingdom (see section four for subtleties portrayal of the utilization and results of this contextual evaluation). figure 1 demonstrates the computational manner for ascertaining summed up cost networks for a given mode. 


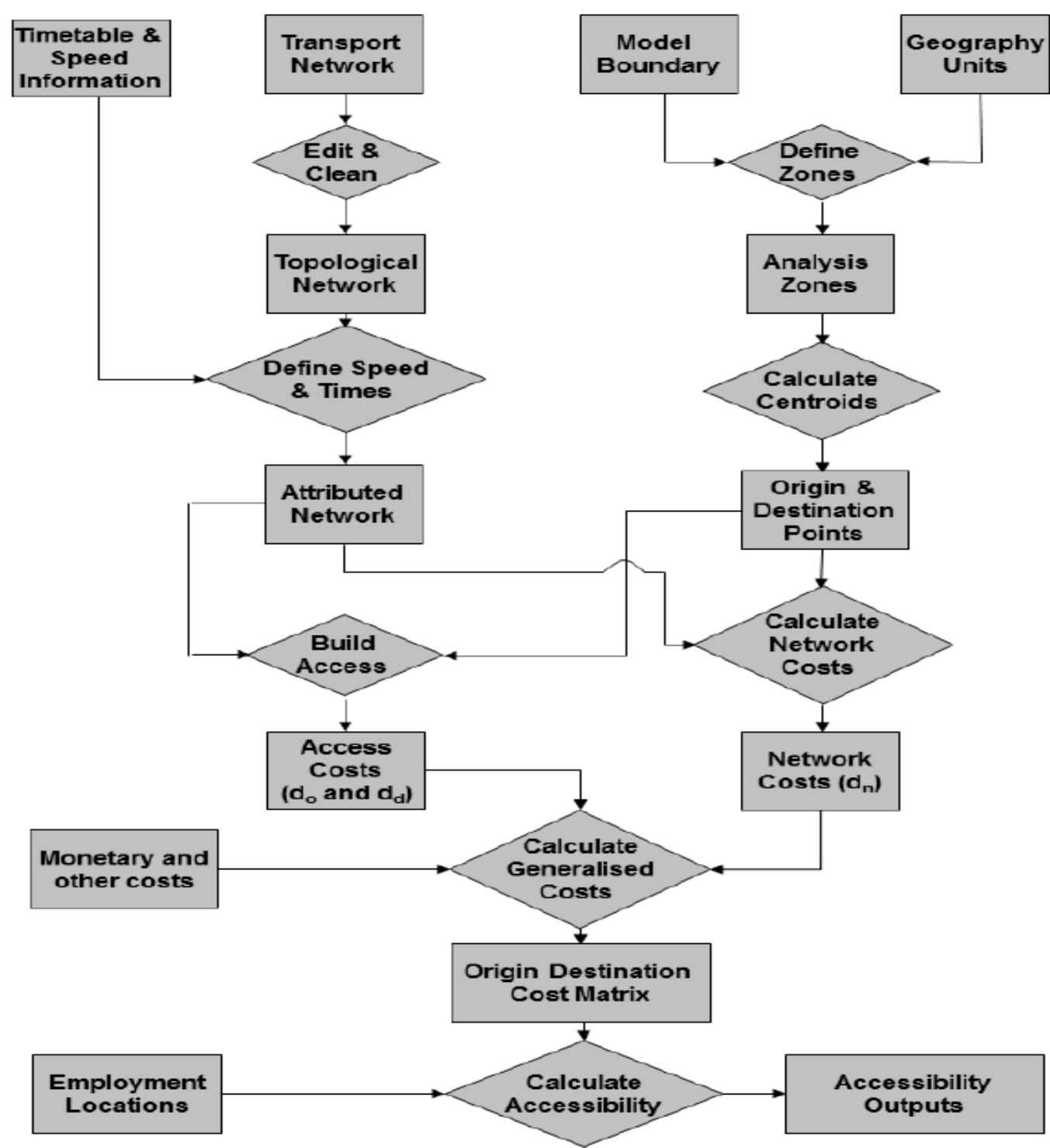

discern 1. Calculation system for networks of summed up rate, and in this way availability measures. artwork regions is probably supplanted via way of various information to parent openness to exceptional places of work.

The summed up price model (determine 1) changed into completed as pursues utilising values in table 1 for the severa terms

1. in the first place, the spatial topography of the version is characterized as a ways as zonal geology and the spatial restriction of research (as an instance for the London contextual evaluation added underneath, the ones are united kingdom Census region facts Wards, i.E., zones on which 2001 uk enumeration yields are accounted for).

2. construct M delivery systems:

A. spoil down, and easy if crucial, the records to assure the right topological shape for making of a spatial system model.

B. Fabricate spatial structures interior GIS programming.

C. decide the duration of every device be a part of from geometry.

D. boom every device connect period with the aid of the usage of the pertinent tour pace to accumulate the motion time for every connection.

3. For $\mathrm{N}$ devices of spatial topography, make a $\mathrm{N} x \mathrm{~N}$ grid of summed up fees for each one of the $\mathrm{M}$ delivery modes (just like the approach delineated through the usage of Benenson et al.):
A. verify the region of the centroid and use it to symbolize the beginning location, and vacation spot of vicinity I.

B. confirm get entry to separation, do, and associated adventure time from centroid to closest device get to area (private and biking modes), or loading up component (open car modes) (determine 2)

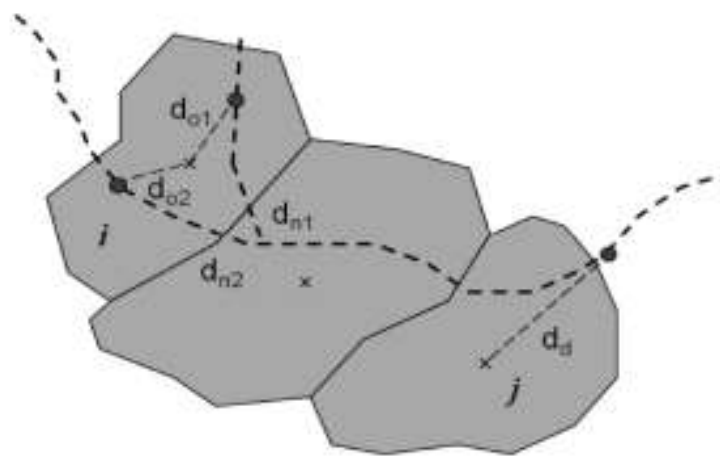

discern 2. Schematic delineation of journey from birthplace I to cause j. 
C. verify maximum restrained (set up) way, dn, amongst deliver and purpose centroids using Dijkstra's calculation [47] (determine 2). maximum constrained publications depending on schedule, in place of get rid of, are figured so you can hold in thoughts expenses of motion. that is advocated with the aid of ESRI's network Analyst enlargement.

D. discern get admission to separation, dd, and related excursion time from motive station or stop (open vehicle) or road get to region (non-public and biking modes) (landing thing) to the

Centroid of the aim area (decide 2). E. Dispense with counter-intuitive adventures (e.G., in which closest station is shared some of the reason and aim) and pass once more a no-records esteem.

Table 1. Basis upgrades actualized in baseline, low and excessive hypothesis conditions (in slight of shipping 2025 report

\begin{tabular}{|c|c|c|c|c|}
\hline T2015 senarie & Road & Bss & Rail & Light Rail \\
\hline Brselue & & & 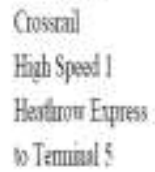 & $\begin{array}{l}\text { Bastrow Tenuinal } 5 \\
\text { ettanoin }\end{array}$ \\
\hline Lotit & $\begin{array}{l}\text { Thretes } \\
\text { Ginteuyy Bridat }\end{array}$ & 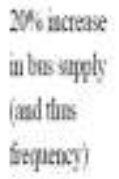 & $\begin{array}{l}\text { Rethe joumey } \\
\text { ent by } 45 \% \text {; }\end{array}$ & 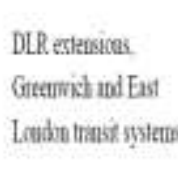 \\
\hline Hiph & 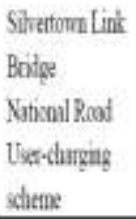 & $\begin{array}{l}\text { Who iacrense } \\
\text { in bes supply. }\end{array}$ & 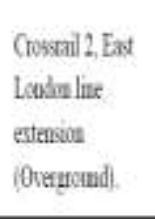 & 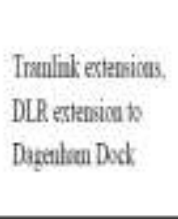 \\
\hline
\end{tabular}

due to private car systems (avenue and biking) most rate components are integrated at the connections themselves, thinking about the truth that non-time factors are often accumulated in a separation based totally completely way. therefore, as an example, the impact of geography on cycling is added about on a connection through manner of-interface premise. Clog charging or special street customer charging plans ought to be included as on-interface fees (i.E., thru strategies for developing adventure times along a connection through rate of Time alternate). See section 4 for a discourse of the London Congestion charge and its guidelines.

All system components (e.G., streets, cycle guides, or railroad strains) are bi-directional. a few road prepare records (e.G., Ordnance Survey ITN inside the uk) carries the usage of heading which means that that it is workable to study courses via unmarried direction frameworks, except for enormous investigations (e.G., the $1500 \mathrm{~km} 2$ of London) such nearby scale variables are not vital for global openness. On a comparable premise, the impact of angle is predicted to affect on cycle travels in addition in the headings.

\section{SOME PACKAGES OF GIS IN METROPOLIS TRANSPORTATION}

the usage of GIS-based totally genuinely frameworks for transportation arranging is later and couple of right packages were archived. Simkowitz (3), Lewis (18), and others observe the usage of GIS frameworks in FHW An and selected united states of the united states branches of transportation for preserving up limited-access highway records bases on the $u$. $\mathrm{S}$. degree. The accompanying phase introduces some gift utilizations of GIS frameworks for city transportation arranging and a few consequences of involvement in in search of to include GIS with transportation fashions.

utilization of a GIS to Generate Inputs to Transportation fashions

Sir Bernard regulation County, Maryland

The Maryland country wide Capital Park and planning fee (M-NCPPC), in Sir Bernard regulation County, Maryland, is one of the early customers of GIS innovation for coordinating transportation arranging facts bases (7, paper on this record with the aid of Anderson). The SPANS GIS programming changed into obtained in 1988 to assist transportation model improvement and information the board. The underlying utilization of SP ANS became to supply thematk (chluropleth) maps of sector diploma data information to the transportation version utilized.

The second and increasingly complex use of SP ANS modified into to provide land use records contributions to a improvement of subarea arranging fashions. The territorial TAZ association of 351 zones done in usual transportation arranging grow to be considered unreasonably coarse for subarea ace arranging, and evaluation of community stage strategies for transportation framework the board (TSM). in order to show little zones, every other more and more nitty gritty area framework became created and coded to work with the EMME/2 computer transportation demonstrating programming. The land use input facts for the transportation model had been set up with the useful resource of SPANS.la Metropolitan location

The Southern California affiliation of Governments (SCAG), the arranging enterprise for the los angeles metropolitan locale, is building up a land use-transportation model to assess prolonged haul development designs. The huge volume of records and the want to narrate data from numerous spatial levels required the protection of all records under a GIS. Bend/information changed into picked due to the fact the GIS scenario to provide an protected facts base. The facts base consists of an series of information. but some financial elements for an assortment of spatial stages, it consists of the digitized stop-all strategies of all networks inside the locale, a specific portrayal of the road set up, and the careful region _of usually bosses. gift area uses may be recognized through aerophotography and after that digitized and converged with the the relaxation of the data base.

Incorporating a Land Use-Transportation version With a GIS

The cause of this exertion is to sign up for the POLIS land use-transportation version created thru the affiliation of Bay Governments (ABAG) with a GIS bundle. POLIS (19) has been utilized by ABAG for the cause that 1985 to assess future motion of population and hotels within the San Francisco Bay place. Its real distinction from Lowry-primarily based definitely land use models is that future conjectures of occupations and accommodations 
region are expressly stimulated by means of the transportation framework, just as accommodations accessibility, vicinity to organization focuses, zonal attractive top notch, and so on. For the cause that model is given a role as a scientific programming issue, families and paintings designation

moreover, trip movement examples are assessed in a solitary cycle and are regular with each different and the land use imperatives.

The incorporation method consists of of noteworthy errands: (a) consolidating the model with a GIS package deal deal to reveal the aftereffects of the distribution on a manual, and (b) building up a GIS facts base with all big arranging data that produces an appropriate contributions for POLIS.

\section{ENDS}

This paper has exhibited a GIS-based totally tool that has been created to empower quick portrayal of automobile charges and openness over extensive spatial regions making use of proper away to be had statistics. The consequences of this device can be displayed in an collection of strategies, which include as plots or charts, and as spatial maps of summed up charge or availability. the key advantage of this approach is to empower quick examination of the impacts of new basis improvements on openness at a nearby to town-massive scale, and the correlation of availability designs among contending modes. Te Brömmelstroet et al. [22] confirmed that chiefs find out "seen manual based sincerely media to be an exceedingly beneficial device for conveying openness" and that "organizers lean within the route of maps, whilst delivery organizers are greater quiet at the same time as given quantitative yields". The device delivered proper proper here has been presupposed to provide every such yields utilising broadly reachable GIS programming. furthermore, this tool is given as a loose upload-on for preferred GIS and might employ overtly on hand records along the ones strains tending to concerns of a massive quantity of close by authorities associations that don't have the time, cash, facts, and computational aptitudes to strive openness research. application to greater London demonstrates that systems of diverse vehicle modes may be examined over large spatial scales, and uncovers full-size spatial fluctuation in car costs and art work

Openness. business corporation openness is confirmed to be an hard capability of car mode, installation structure, area of occupations and adventure reason.

\section{REFERENCES}

1 P. Burroughs. standards of Geographical information structures. Clarendon Press, Oxford, England, 1986.

2 Proc., 1987, 1988, and 1989 Annual UR/SA meetings. URISA, Washington, D.C., 1989.

3 three. H. Simkowitz. Transportation packages of Geographical data structures. computer systems, surroundings and concrete systems. Vol. 12, No. four, 1988, pp. 253-271.

4 four. T. L. Nyerges and okay. J. Dueker. Geographic information systems in Transportation. specialised file, place of work of planning, FHWA, U.S. department of Transportation, 1988.
5 5. M. Francis Francis Bacon and D. Moyer. Proc., 1990 Geographic statistics structures (GJS) for Transportation Symposium. AASHTO, Washington, D.C., 1990.

6 6. R. Cervero. Rural Gridlock. area for city coverage, New Brunswick, N.J., 1986.

7 7. M. Replogle. becoming a member of of a Geographic information device With pc Transportation models for Land Use and Transportation making plans. Proc., 2d convention on software of Transportation making plans strategies, college of North Carolina, Charlotte, 1989.

\section{AUTHORS DETAILS}

\section{AAMUDALAPELLI ANJALI}

Research scholar Department of Civil Engineering from University of Technology,Jaipur. She received B.Tech in 2013 from Symbiosis (JNTU Hyderabad), and M.tech in 2016 from Malla Reddy Institute Of technology and Science,(JNTU Hyderabad). anjali2204@gmail.com

Dr. Santhosh Kumar, Professor In Civil Dept, University Of Technology, Jaipur. Scholastically advanced Educationist with rich scholarly and authoritative experience; offering a famous profession crossing more than 15 years in different Engineering Colleges. Achieve with sound reputation of inventive academic accomplishments. Master in arranging, sorting out, planning and checking a wide range of curricular and co-curricular exercises for the general advancement character of understudies and the board of the organization Sabbidvenkat2017@gmail.com 